\title{
Supporting Information: On $\mathrm{Mn}^{2+}$ EPR Probing
}

\author{
of the Ferroelectric Transition and Absence of
}

Magnetoelectric Coupling in Dimethylammonium

Manganese Formate $\left(\mathrm{CH}_{3}\right)_{2} \mathrm{NH}_{2} \mathrm{Mn}(\mathrm{HCOO})_{3}$, a

Metal-Organic Complex with the Pb-Free

\section{Perovskite Framework}

Nandita Abhyankar ${ }^{\#}$, Sylvain Bertaina ${ }^{\dagger, *}$, Naresh S. Dalal ${ }^{\#, *}$

\# Department of Chemistry and Biochemistry, Florida State University, Tallahassee, FL, 323064390, USA

$\dagger$ Aix-Marseille Université, CNRS, IM2NP UMR7334, 13397 cedex 20, Marseille, France 


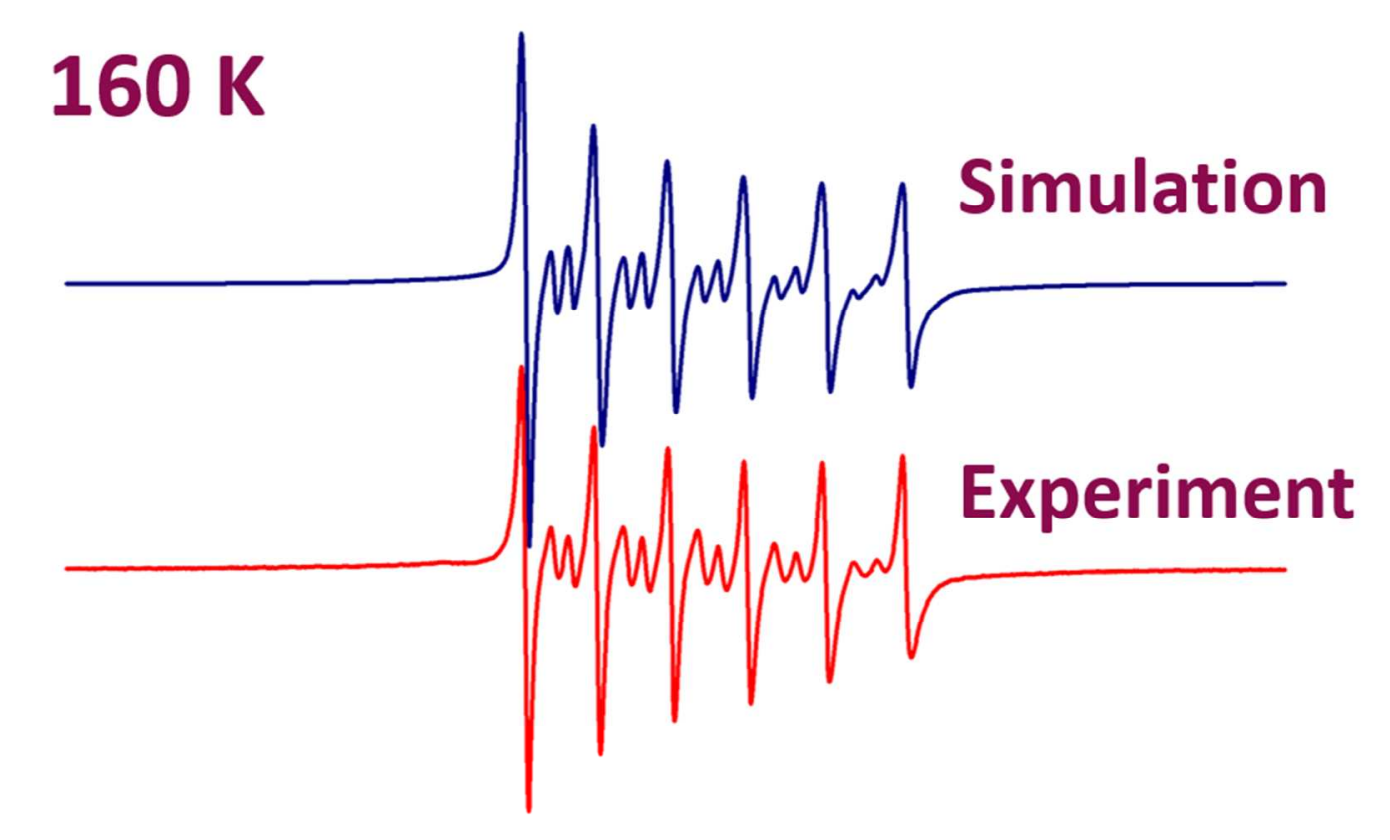

\section{0 Field (Gauss)}

Figure 1: Experimental and simulated EPR spectrum for DMZnF with $0.5 \%$ of $\mathrm{Mn}^{2+}$ powder in the high-temperature R3c phase. Simulations using the EasySpin toolbox in Matlab yield the following parameters: $\mathrm{S}=5 / 2, \mathrm{I}=5 / 2$, hyperfine constant $\mathrm{A}=265 \mathrm{MHz}$, axial crystal field $\mathrm{D}=250$ $\mathrm{MHz}$, Gaussian distribution of the crystal field of $150 \mathrm{G}$. 


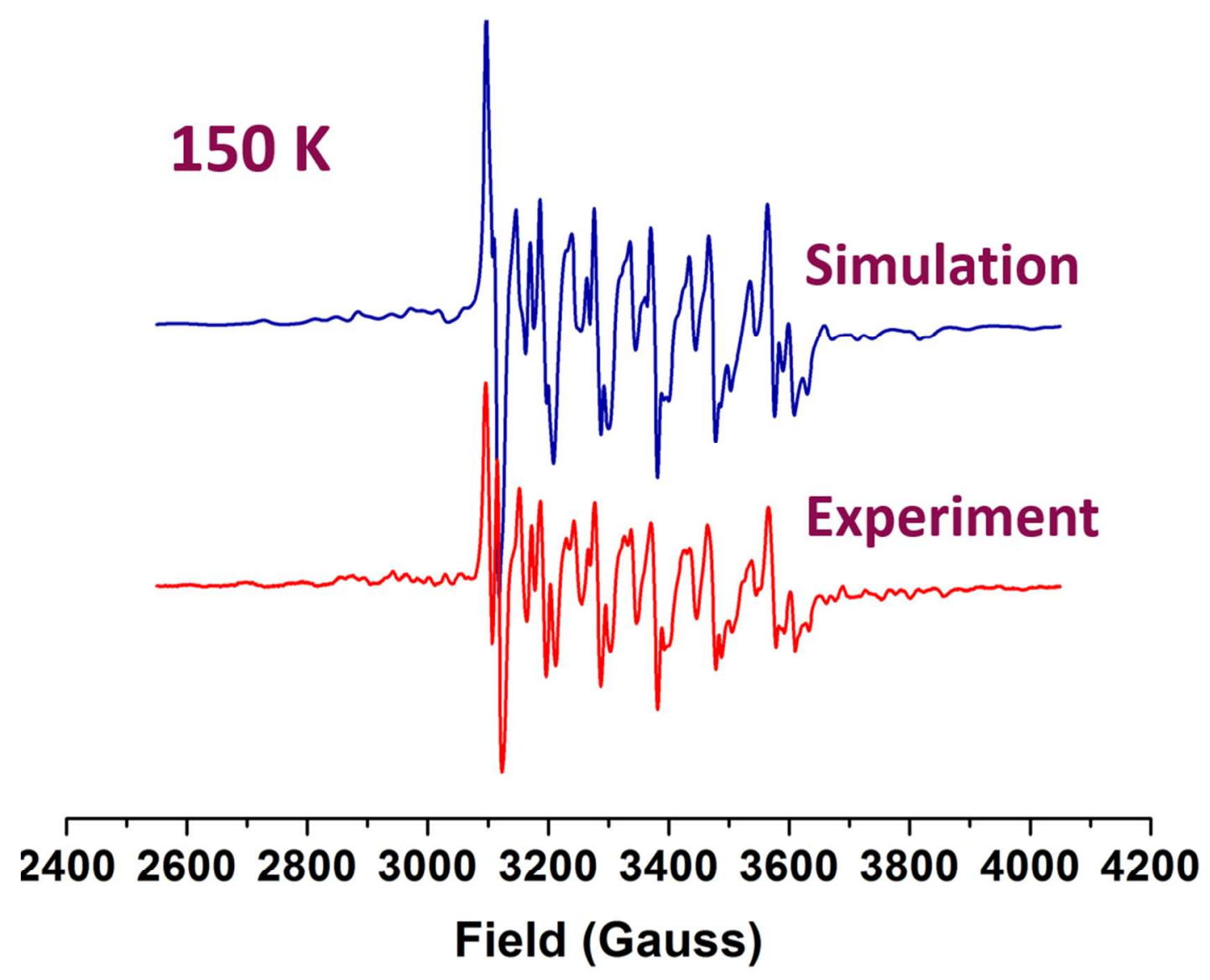

Figure 2: Experimental and simulated EPR spectrum for $\mathrm{DMZnF}$ with $0.5 \%$ of $\mathrm{Mn}^{2+}$ powder in the low-temperature $\mathrm{Cc}$ phase. Simulations using the EasySpin toolbox in Matlab yield the following parameters: $\mathrm{S}=5 / 2, \mathrm{I}=5 / 2$, hyperfine constant $\mathrm{A}=265 \mathrm{MHz}$, axial crystal field $\mathrm{D}=400$ $\mathrm{MHz}$, rhombic crystal field $\mathrm{E}=60 \mathrm{MHz}$, Gaussian distribution of the crystal field of $=10 \mathrm{G}$. 